\title{
Highly Selective Removal of Trace Isomers by Nonporous Adaptive Pillararene Crystals for Chlorobutane Purification
}

\author{
Yujuan Zhou, Kecheng Jie, ${ }^{*}$ Run Zhao, Errui Li and Feihe Huang*
}

State Key Laboratory of Chemical Engineering, Center for Chemistry of

High-Performance \& Novel Materials, Department of Chemistry, Zhejiang University, Hangzhou, Zhejiang 310027, P. R. China; Fax and Tel: +86-571-8795-3189;

Email: jiekecheng@zju.edu.cn; fhuang@zju.edu.cn

\section{Supporting Information (26 pages)}

1. Materials $\quad$ S2

2. Methods $\quad$ S2

3. Crystallography Data S4

4. Characterization of Desolvated EtP5 Crystals (EtP5 $\alpha$ ) and EtP6 crystals (EtP6 $\beta) \quad$ S6

5. Vapor-Phase Adsorption Measurements $\quad \mathrm{S} 11$

6. Recyclability of EtP5 $\alpha$ and EtP6 $\beta$ Crystals $\quad$ S23

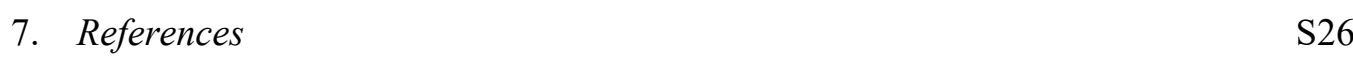




\section{Materials}

$p$-Diethoxybenzene was purchased from JK Chemicals and used as received. All other chemicals, including 1-chlorobutane (1-CB) and 2-chlorobutane (2-CB), were purchased from Sigma-Aldrich and used as received. EtP5 and EtP6 were synthesized as described previously. ${ }^{\mathrm{S} 1}$ Desolvated crystalline EtP5 (EtP5 $\alpha$ ) was recrystallized from tetrahydrofuran and dried under vacuum at $100{ }^{\circ} \mathrm{C}$ overnight. Desolvated crystalline EtP6 (EtP6 $\beta)$ was recrystallized from acetone and dried under vacuum at $140{ }^{\circ} \mathrm{C}$ overnight.

\section{Methods}

\subsection{Solution NMR}

Solution ${ }^{1} \mathrm{H}$ NMR spectra were recorded at $400.13 \mathrm{MHz}$ using a Bruker Avance 400 NMR spectrometer.

\subsection{Thermogravimetric Analysis}

Thermogravimetric (TGA) analysis was carried out using a Q5000IR analyzer (TA Instruments) with an automated vertical overhead thermobalance. The samples were heated at the rate of $10^{\circ} \mathrm{C} / \mathrm{min}$ using $\mathrm{N}_{2}$ as the protective gas.

\subsection{Powder X-Ray Diffraction}

PXRD data before and after vapor soption were collected on a Rigaku Ultimate-IV $\mathrm{X}$-ray diffractometer operating at $40 \mathrm{kV} / 30 \mathrm{~mA}$ using the $\mathrm{Cu} \mathrm{K \alpha}$ line $(\lambda=1.5418 \AA)$. Data were measured over the range of $5-40^{\circ}$ in $5^{\circ} / \mathrm{min}$ steps over $7 \mathrm{~min}$.

\subsection{Single Crystal Growth}

Single crystals of 1-CB loaded EtP5 were grown by slow evaporation: $5 \mathrm{mg}$ of dry EtP5 powders were put in a small vial where $2 \mathrm{~mL}$ of 1-CB was added. The resultant transparent solution was allowed to evaporate slowly to give colourless crystals in 5 to 10 days.

Single crystals of 1-CB and 2-CB loaded EtP6 were grown by slow evaporation: $5 \mathrm{mg}$ of dry EtP6 powders were put in a small vial where $2 \mathrm{~mL}$ of 1-CB or 2-CB was added. The resultant transparent solution was allowed to evaporate slowly to give colourless crystals in 5 to 10 days.

\subsection{Single Crystal X-ray Diffraction}


Single crystal X-ray data sets were measured on a Rigaku MicroMax-007 HF rotating anode diffractometer (Mo-K $\alpha$ radiation, $\lambda=0.71073 \AA$, Kappa 4-circle goniometer, Rigaku Saturn724+ detector). Unless stated, solvated single crystals, isolated from the crystallization solvent, were immersed in a protective oil, mounted on a MiTeGen loop, and flash cooled under a dry nitrogen gas flow. Empirical absorption corrections, using the multi-scan method, were performed with the program SADABS. ${ }^{\mathrm{S}, \mathrm{S} 3}$ Structures were solved with SHELXD ${ }^{\mathrm{S} 4}$ or SHELXT, ${ }^{\mathrm{S} 5}$ or by direct methods using SHELXS, ${ }^{\mathrm{S} 6}$ refined by full-matrix least squares on $|F|^{2}$ by SHELXL, ${ }^{\mathrm{S} 7}$ and interfaced through the programme OLEX2. ${ }^{\mathrm{S} 8}$ Unless stated, all non-H-atoms were refined anisotropically, and all $\mathrm{H}$-atoms were fixed in geometrically estimated positions and refined using the riding model. Supplementary CIFs, which include structure factors, are available free of charge from the Cambridge Crystallographic Data Centre (CCDC) via www.ccdc.cam.ac.uk/data_request/cif.

\subsection{Gas Chromatography}

Gas chromatography (GC) analysis: GC measurements were carried out using an Agilent 7890B instrument configured with a FID detector and a DB-624 column (30 $\mathrm{m} \times 0.53 \mathrm{~mm} \times 3.0 \mu \mathrm{m})$. Samples were analyzed using headspace injections and were performed by incubating the sample at $150{ }^{\circ} \mathrm{C}$ for 10 minutes followed by sampling 1 $\mathrm{mL}$ of the headspace. The following GC method was used: the oven was programmed from $50{ }^{\circ} \mathrm{C}$, ramped at $10{ }^{\circ} \mathrm{C} \mathrm{min}^{-1}$ increments to $150{ }^{\circ} \mathrm{C}$ with 15 min hold; the total run time was $25 \mathrm{~min}$; injection temperature $250{ }^{\circ} \mathrm{C}$; detector temperature $280{ }^{\circ} \mathrm{C}$ with hydrogen, air, and make-up flow-rates of 35,350 , and $35 \mathrm{~mL} \mathrm{~min}^{-1}$, respectively;

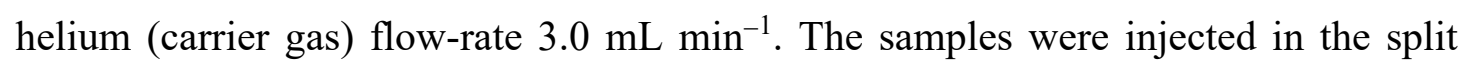
mode (30:1).

\subsection{Gas Sorption Measurement}

Low-pressure gas adsorption measurements were performed on a Micrometritics Accelerated Surface Area and Porosimetry System (ASAP) 2020 surface area analyzer. Samples were degassed under dynamic vacuum for $12 \mathrm{~h}$ at $60{ }^{\circ} \mathrm{C}$ prior to each measurement. $\mathrm{N}_{2}$ isotherms were measured using a liquid nitrogen bath $(77 \mathrm{~K})$.

\subsection{Vapor Sorption Measurement}

1-CB and 2-CB sorption isotherms were measured via Micromeritics 3Flex. Samples were degassed under dynamic vacuum for $12 \mathrm{~h}$ at $120^{\circ} \mathrm{C}$ prior to each measurement. These isotherms were collected at $25^{\circ} \mathrm{C}$ by monitoring the volume change. 


\section{Crystallography Data}

Table S1. Experimental single crystal X-ray data for EtP6 structures.

\begin{tabular}{|c|c|c|}
\hline & 1-CB@EtP6 & $(2-\mathrm{CB})_{2} @ \mathrm{EtP}^{\mathrm{a}}$ \\
\hline Crystallisation Solvent & $1-\mathrm{CB}$ & $2-\mathrm{CB}$ \\
\hline Collection Temperature & $298 \mathrm{~K}$ & $110 \mathrm{~K}$ \\
\hline Formula & $\mathrm{C}_{70} \mathrm{H}_{93} \mathrm{ClO}_{12}$ & $\mathrm{C}_{74} \mathrm{H}_{102} \mathrm{Cl}_{2} \mathrm{O}_{12}$ \\
\hline$M r$ & 1161.89 & 1254.52 \\
\hline Crystal Size [mm] & $0.04 \times 0.08 \times 0.09$ & $0.1 \times 0.06 \times 0.03$ \\
\hline Crystal System & Monoclinic & Triclinic \\
\hline Space Group & $P 2_{1} / n$ & $P-1$ \\
\hline$a[\AA]$ & $11.470(2)$ & $12.3608(10)$ \\
\hline$b[\AA]$ & $13.122(4)$ & $14.6450(12)$ \\
\hline$c[\AA]$ & $22.181(4)$ & $23.0103(17)$ \\
\hline$\alpha\left[^{\circ}\right]$ & & $79.480(5)$ \\
\hline$\beta\left[^{\circ}\right]$ & $91.554(17)$ & $74.424(5)$ \\
\hline$\gamma\left[^{\circ}\right]$ & & $65.366(5)$ \\
\hline$V\left[\AA^{3}\right]$ & $3337.2(13)$ & $3635.4(5)$ \\
\hline$Z$ & 2 & 2 \\
\hline $\mathrm{D}_{\text {calcd }}\left[\mathrm{g} \mathrm{cm}^{-3}\right]$ & 1.156 & 1.061 \\
\hline$\mu\left[\mathrm{mm}^{-1}\right]$ & 0.973 & 0.579 \\
\hline $\mathrm{F}(000)$ & 1252 & 1252 \\
\hline $2 \theta$ range $\left[{ }^{\circ}\right]$ & $7.82-129.98$ & $6.52-110.66$ \\
\hline Reflections collected & 13658 & 40930 \\
\hline $\begin{array}{l}\text { Independent reflections, } \\
R_{\text {int }}\end{array}$ & $5385,0.0807$ & $13630,0.0897$ \\
\hline Obs. Data $[I>2 \sigma(I)]$ & 2803 & 8708 \\
\hline Data /restraints / & $5385 / 48 /$ & $13630 / 49 /$ \\
\hline parameters & 404 & 810 \\
\hline $\begin{array}{l}\text { Final } R_{1} \text { values }(I> \\
2 \sigma(I))\end{array}$ & 0.0638 & 0.2134 \\
\hline Final $R_{1}$ values (all data) & 0.1397 & 0.2539 \\
\hline $\begin{array}{l}\text { Final } w R\left(F_{2}\right) \text { values (all } \\
\text { data) }\end{array}$ & 0.1692 & 0.4429 \\
\hline Goodness-of-fit on $F^{2}$ & 1.018 & 0.89 \\
\hline $\begin{array}{l}\text { Largest difference peak } \\
\text { and hole }\left[\mathrm{e} \cdot \mathrm{A}^{-3}\right]\end{array}$ & $0.211 /-0.237$ & $1.361 /-0.509$ \\
\hline CCDC & 1987391 & 1987393 \\
\hline
\end{tabular}

${ }^{\text {a }}$ The $R_{1}$ value is relatively high, even when SQUEEZE routine in PLATON is employed. It may be due to the slightly disorder of the 2-CB guest molecule. Since EtP6 is pure organic with only C and O, the disorder $\mathrm{Cl}$ atoms of the guests contribute a lot to the $R_{1}$ value. Nevertheless, other techniques unambiguously confirm the existence of the two 2-CB guests. 

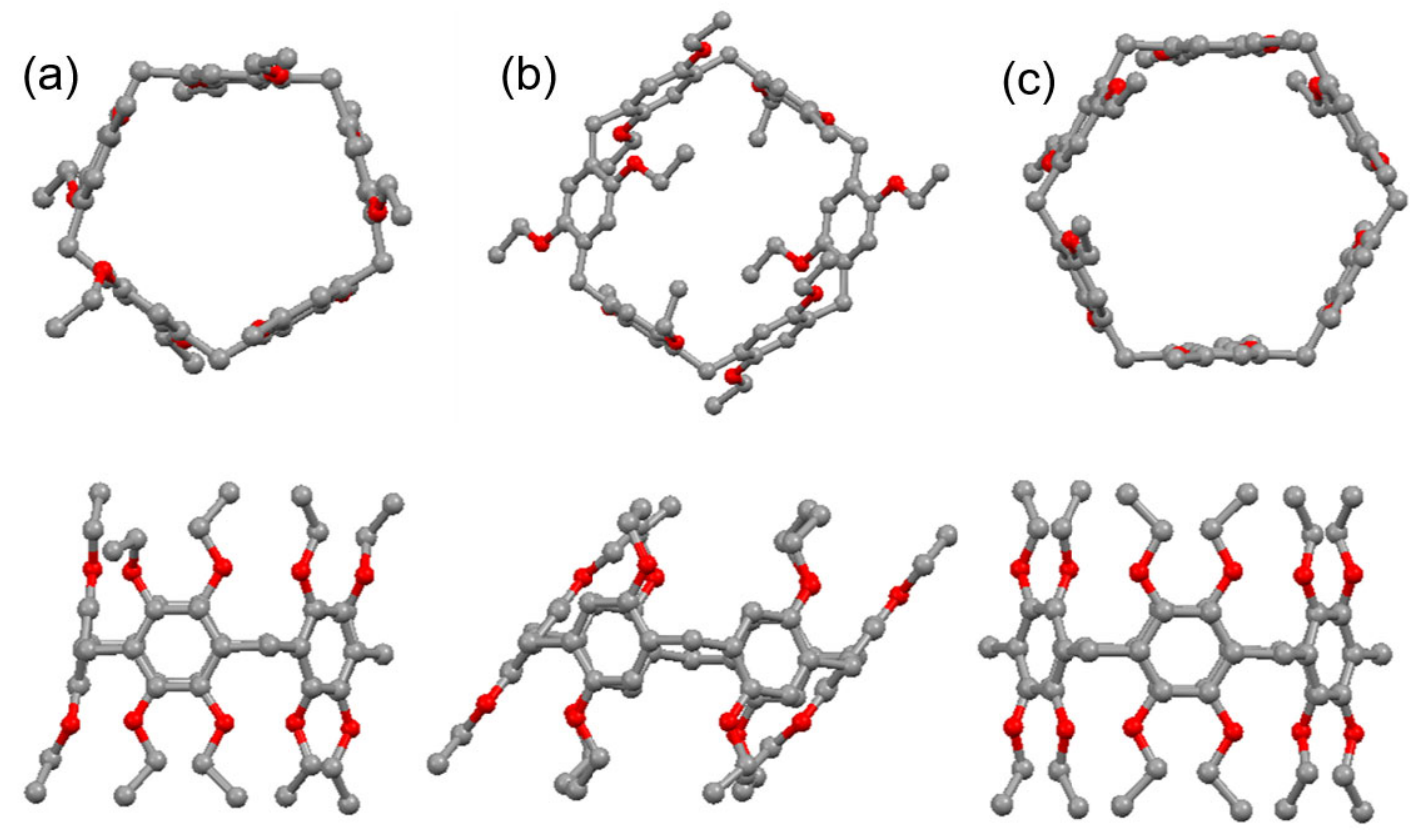

Figure S1. Ball-stick plots from single crystal structures: (a) 1-CB@EtP5, (b) 1-CB@EtP6 and (c) (2-CB)2@EtP6; shown in the cavity (top) and in-plane of the aromatic core (bottom). H-atoms and solvent molecules are omitted for clarity. Not shown on a common scale. 
4. Characterization of Desolvated EtP5 Crystals (EtP5 $\alpha$ ) and EtP6 crystals $(\mathbf{E t P 6} \beta)$

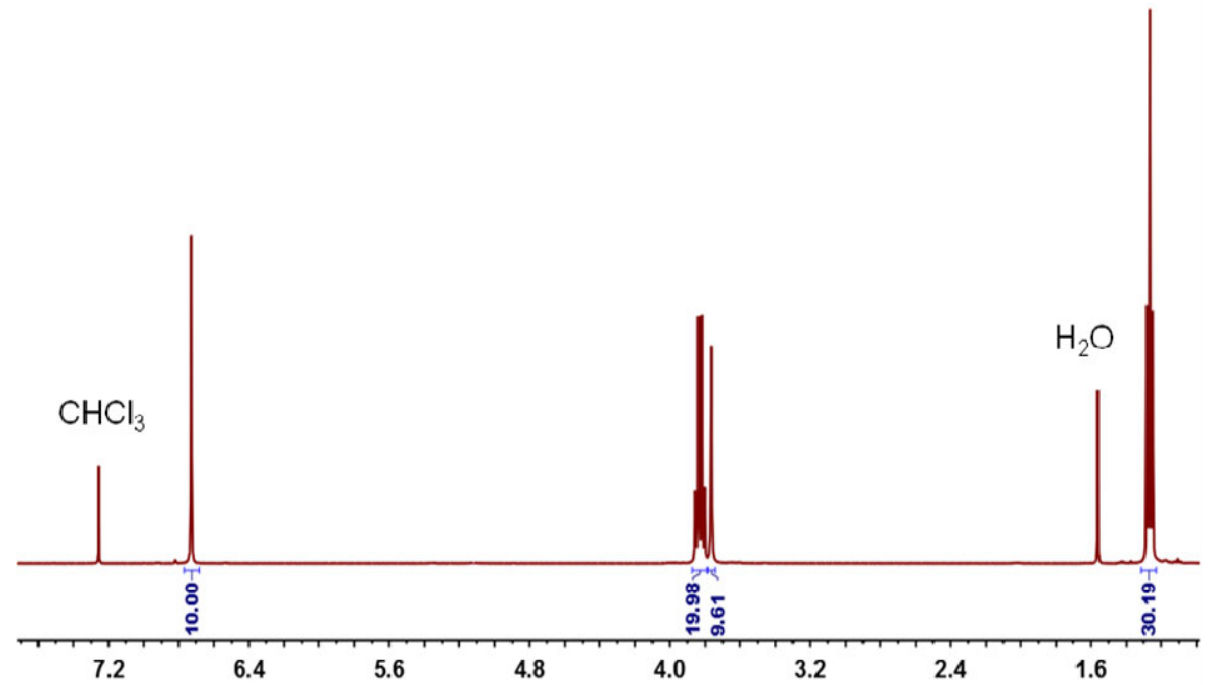

Figure S2. ${ }^{1} \mathrm{H}$ NMR spectrum $\left(400 \mathrm{MHz}, \mathrm{CDCl}_{3}, 293 \mathrm{~K}\right.$ ) of $\mathrm{EtP} 5 \alpha$. The $\mathrm{H}_{2} \mathrm{O}$ peak is from $\mathrm{CDCl}_{3}$.

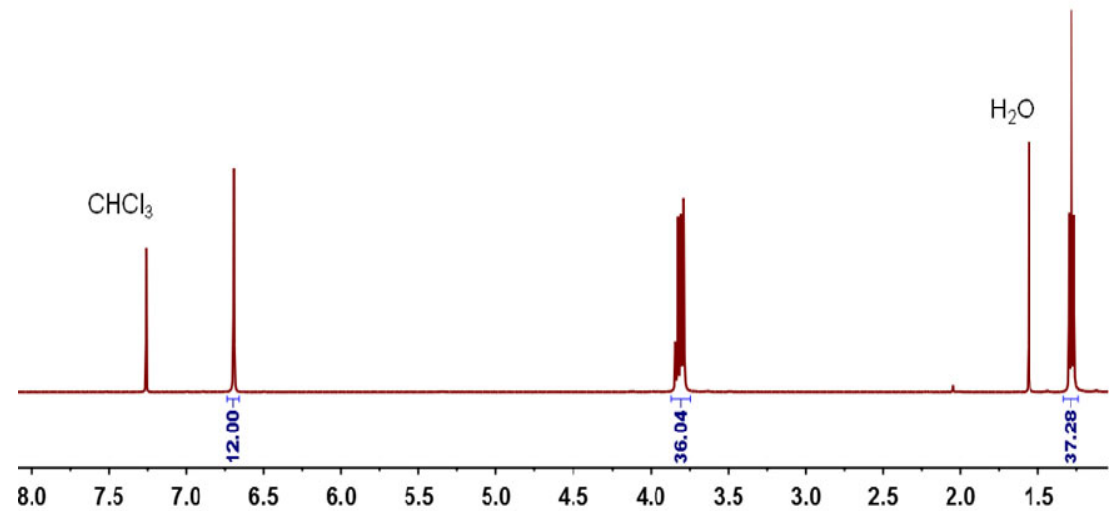

Figure S3. ${ }^{1} \mathrm{H}$ NMR spectrum $\left(400 \mathrm{MHz}, \mathrm{CDCl}_{3}, 293 \mathrm{~K}\right)$ of $\mathrm{EtP} 6 \beta$. The $\mathrm{H}_{2} \mathrm{O}$ peak is from $\mathrm{CDCl}_{3}$. 


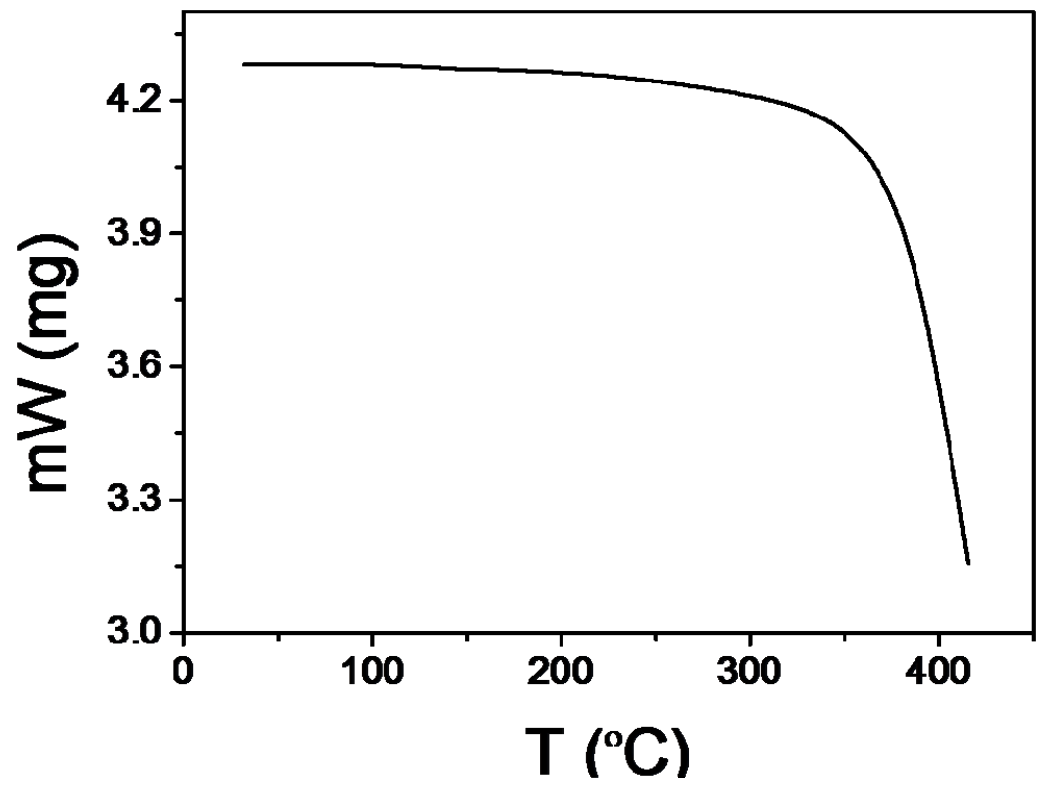

Figure S4. Thermogravimetric analysis of desolvated EtP5.

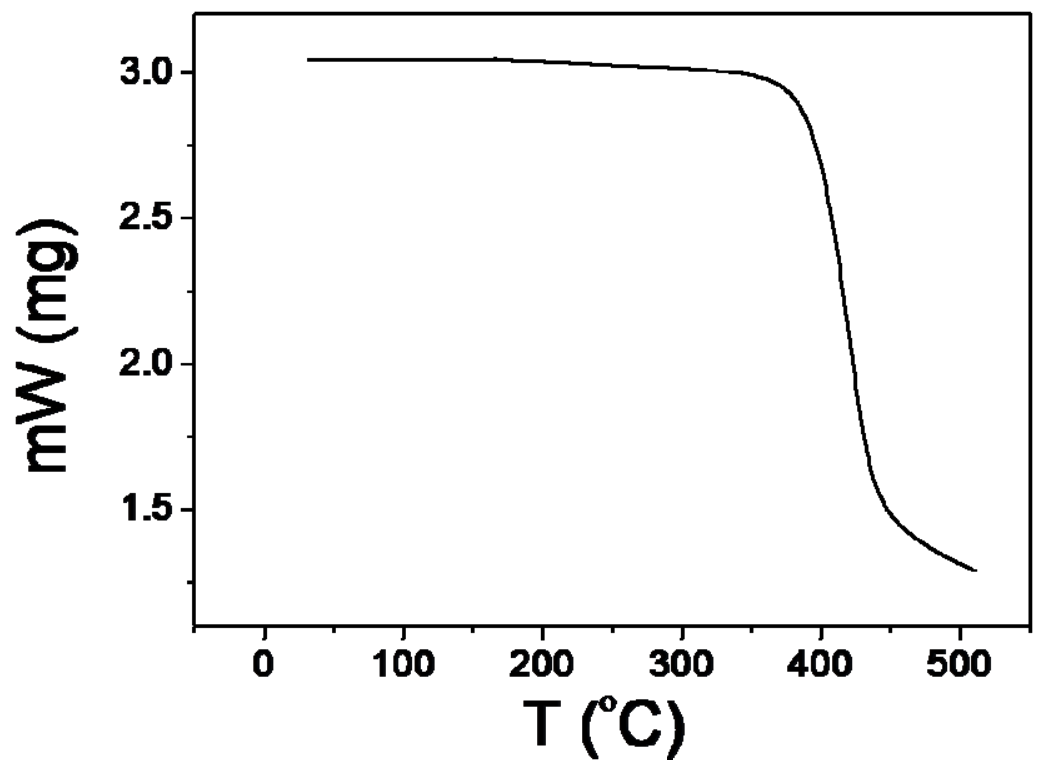

Figure S5. Thermogravimetric analysis of desolvated EtP6. 


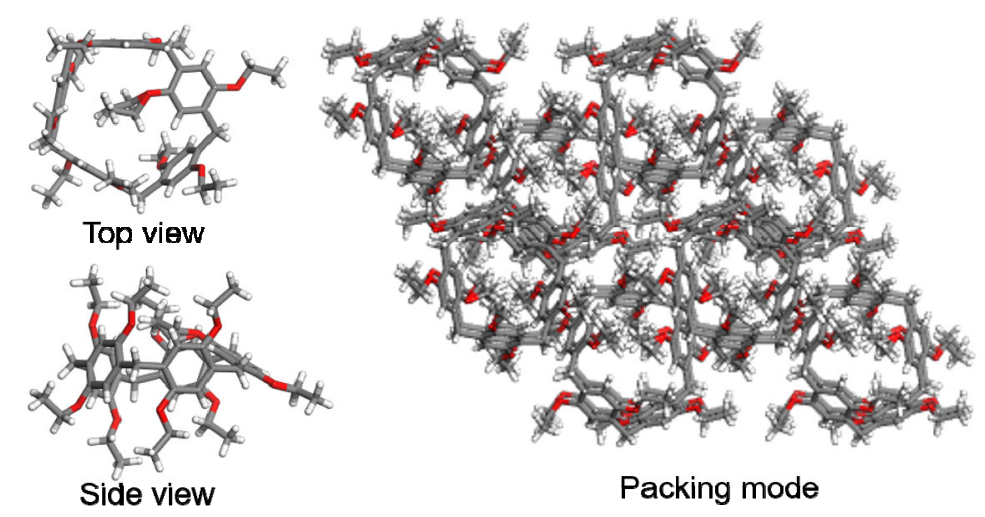

Figure S6. Single crystal structure of guest-free EtP5, which is defined as EtP5 $\alpha .{ }^{\mathrm{S} 9}$

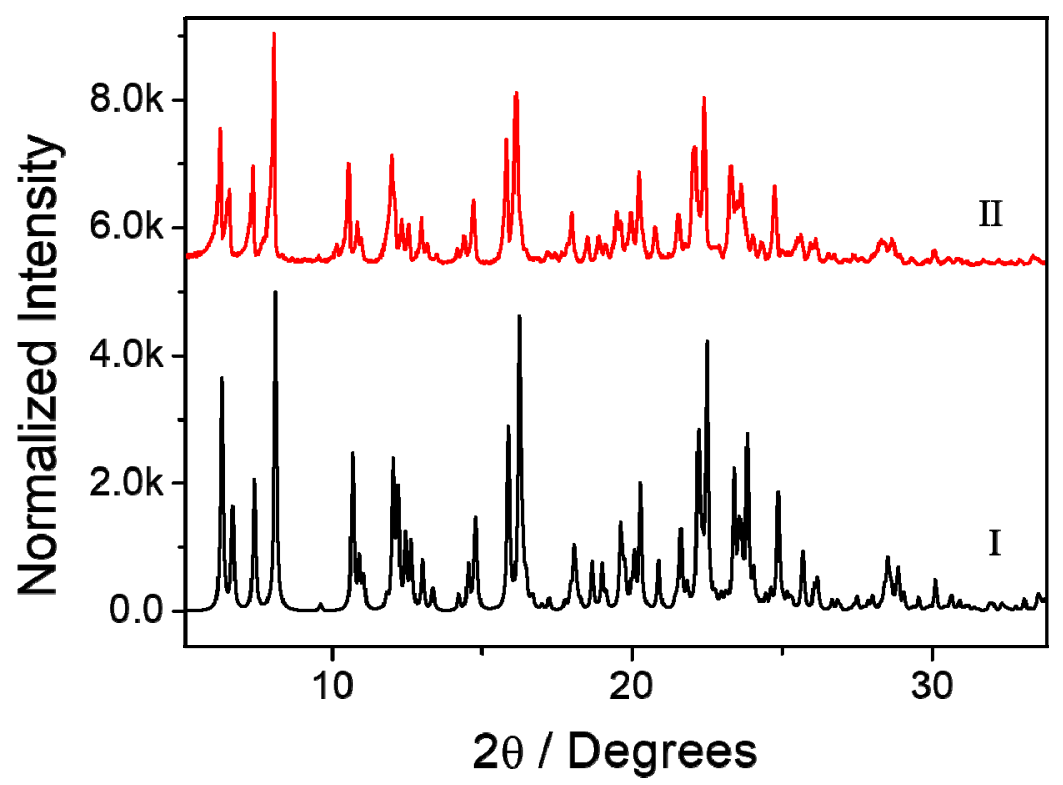

Figure S7. Powder X-ray diffraction patterns: (I) simulated from single crystal structure of guest-free EtP5; (II) activated EtP5 crystals (EtP5 $\alpha$ ). 

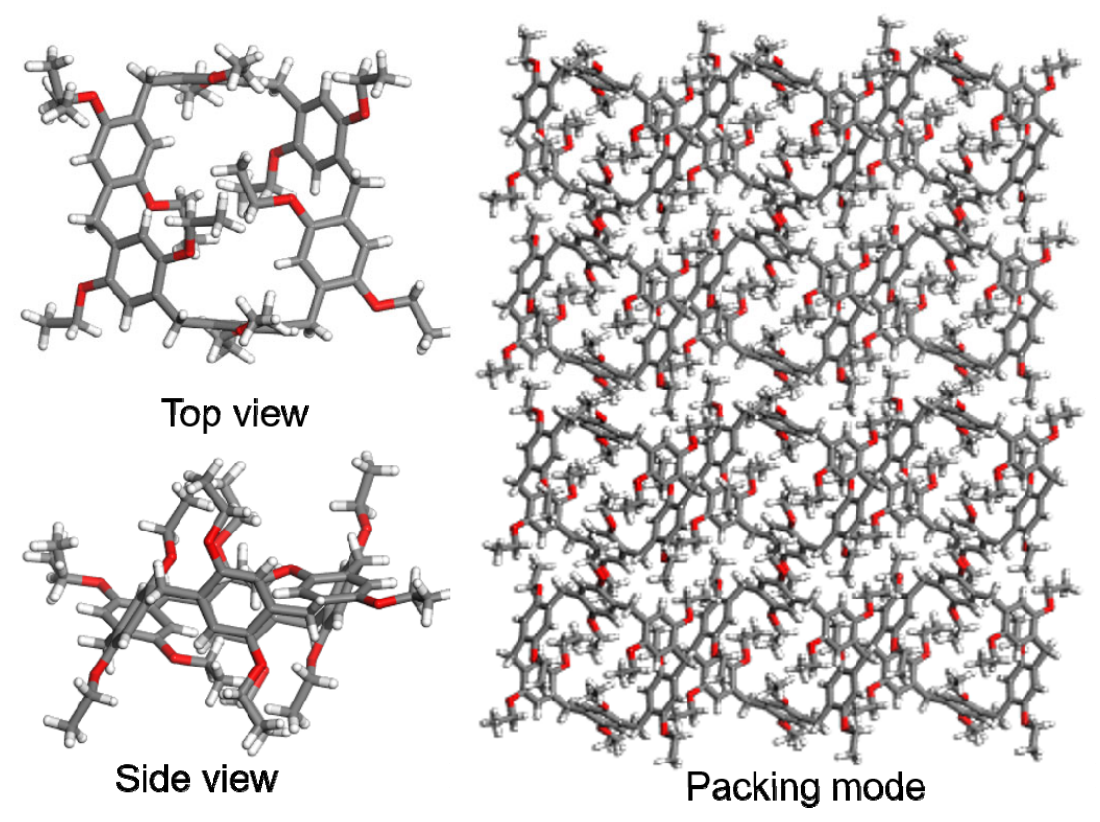

Figure S8. Single crystal structure of thermally stable guest-free EtP6, which is defined as $\operatorname{EtP} 6 \beta{ }^{\mathrm{S} 9}$

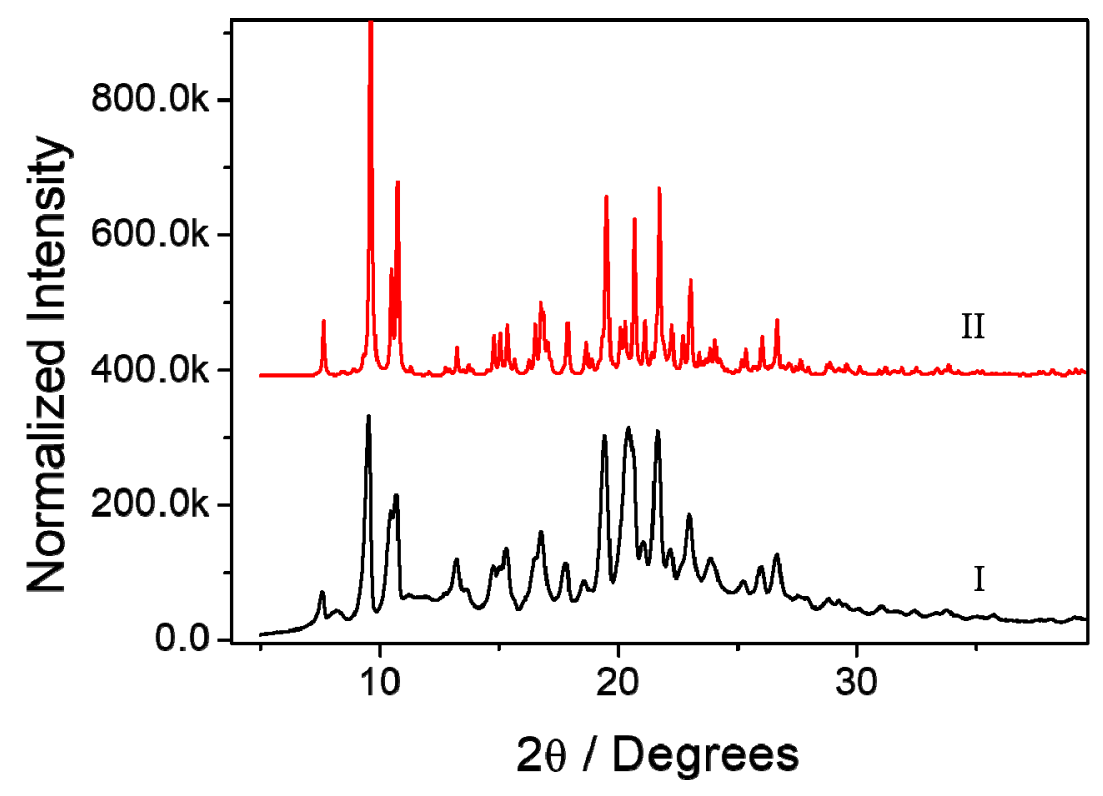

Figure S9. Powder X-ray diffraction patterns: (I) activated EtP6 crystals (EtP6 $\beta$ ); (II) simulated from single crystal structure of guest-free EtP6. 


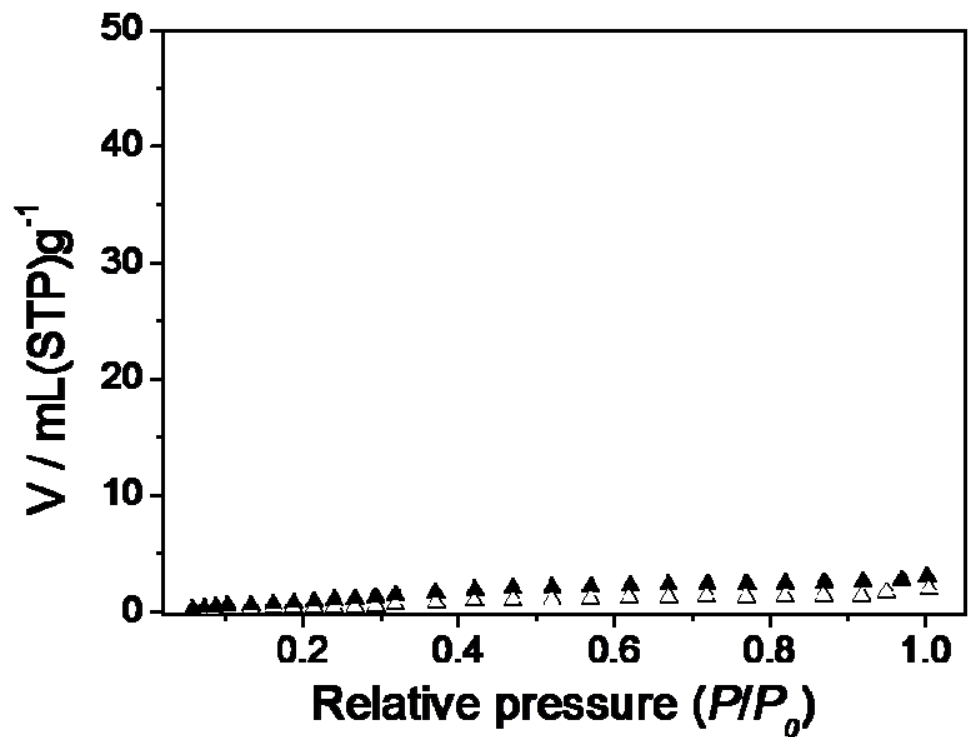

Figure S10. $\mathrm{N}_{2}$ adsorption isotherm of EtP5 $\alpha$. Adsorption, closed symbols; desorption, open symbols.

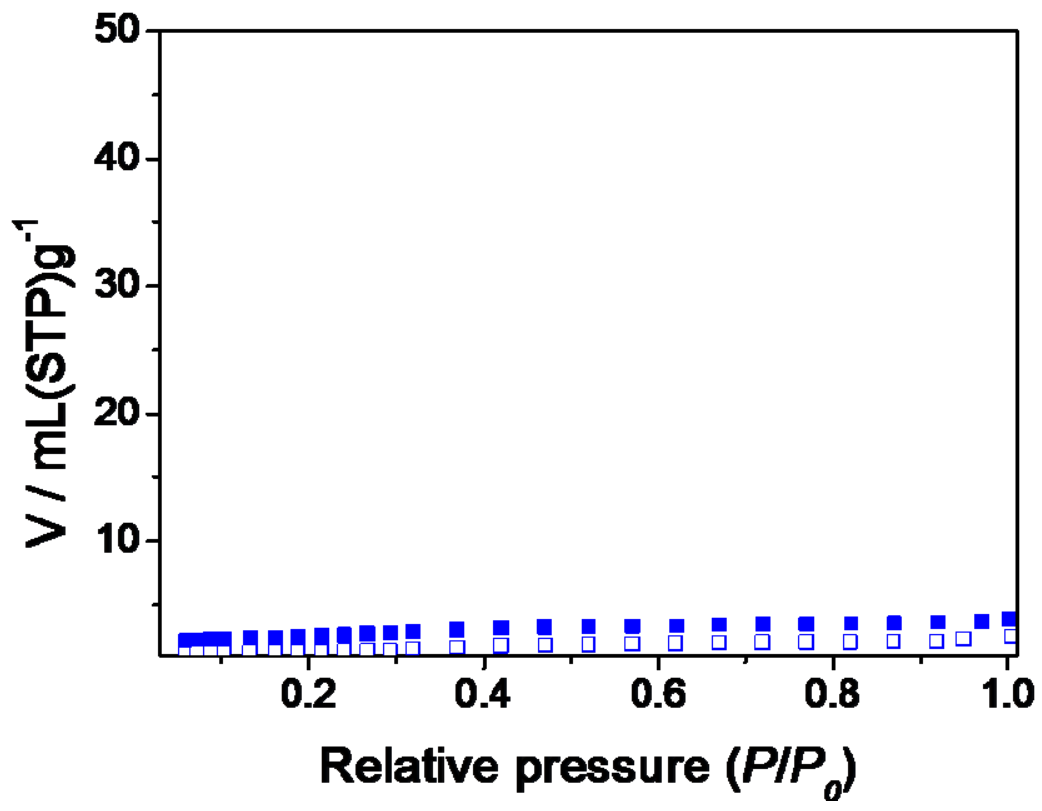

Figure S11. $\mathrm{N}_{2}$ adsorption isotherm of EtP6 $\beta$. Adsorption, closed symbols; desorption, open symbols. 


\section{Vapor-Phase Adsorption Measurements}

\subsection{Single-Component CB Isomer Adsorption Experiments in EtP5 $\alpha$}

${ }^{1} \mathrm{H}$ NMR experiments were performed by dissolving the EtP5 $\alpha$ crystals after vapor sorption in $\mathrm{CDCl}_{3}$. TGA profiles were recorded using EtP5 $\alpha$ crystals after vapor sorption.

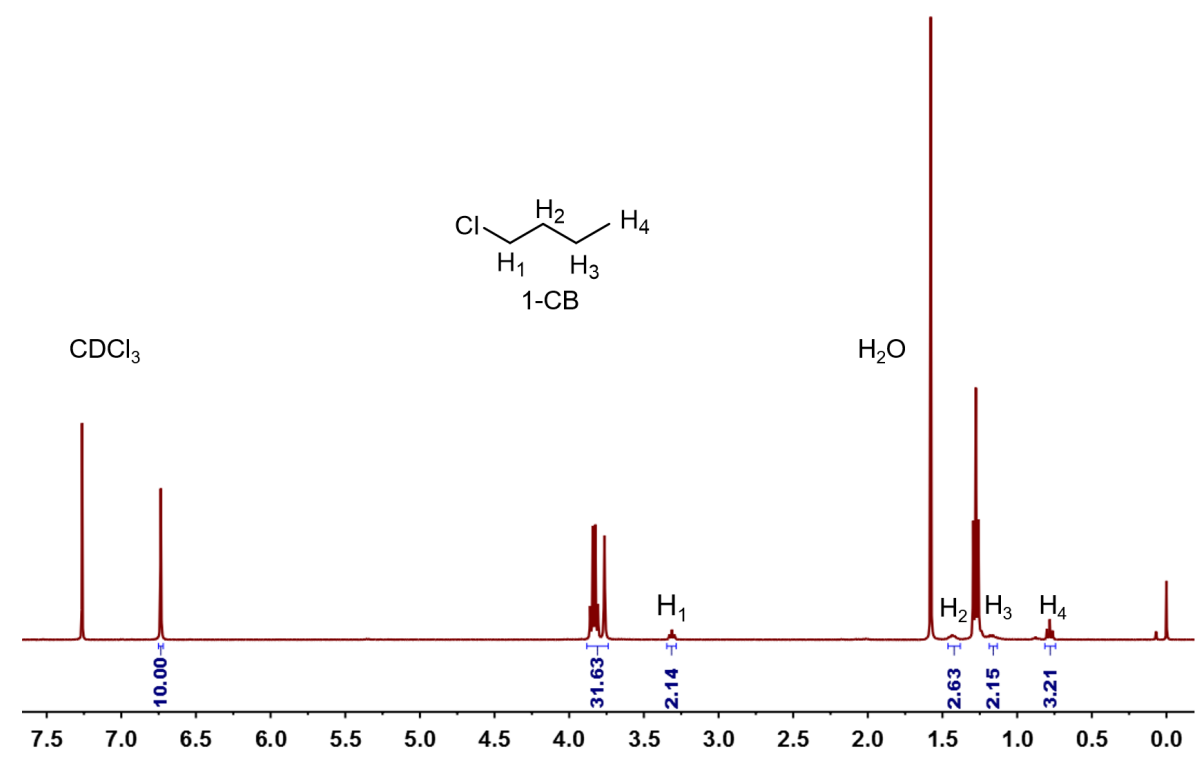

Figure S12. ${ }^{1} \mathrm{H}$ NMR spectrum $\left(400 \mathrm{MHz}, \mathrm{CDCl}_{3}, 293 \mathrm{~K}\right)$ of EtP5 $\alpha$ after adsorption of 1-CB vapor.

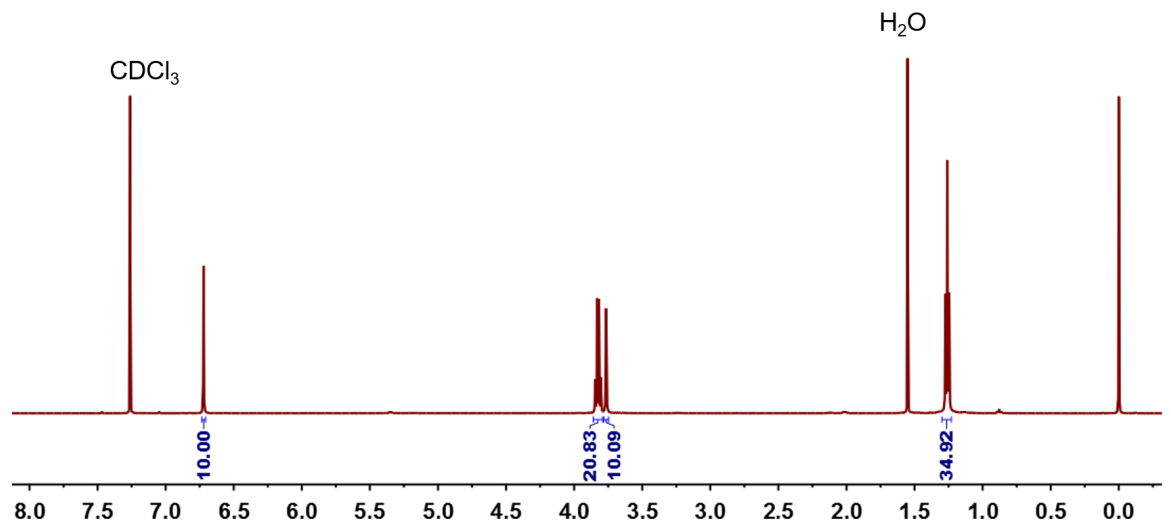

Figure S13. ${ }^{1} \mathrm{H}$ NMR spectrum $\left(400 \mathrm{MHz}, \mathrm{CDCl}_{3}, 293 \mathrm{~K}\right)$ of EtP5 $\alpha$ after adsorption of 2-CB vapor. 


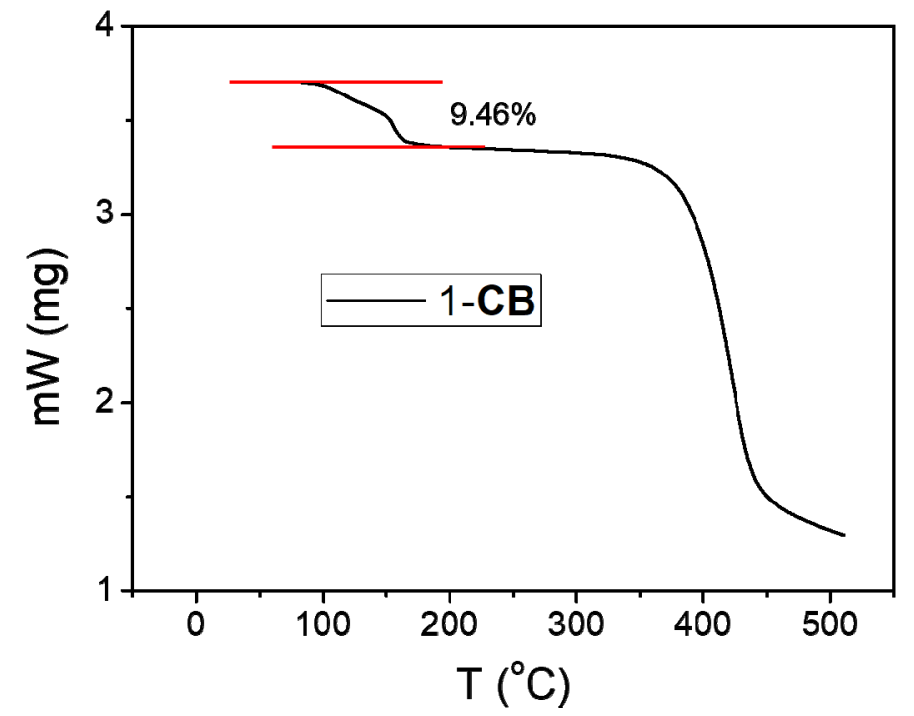

Figure S14. Thermogravimetric analysis of EtP5 $\alpha$ after adsorption of 1-CB. The weight loss below $160^{\circ} \mathrm{C}$ can be calculated as $1.051-\mathrm{CB}$ molecule per EtP5 molecule.

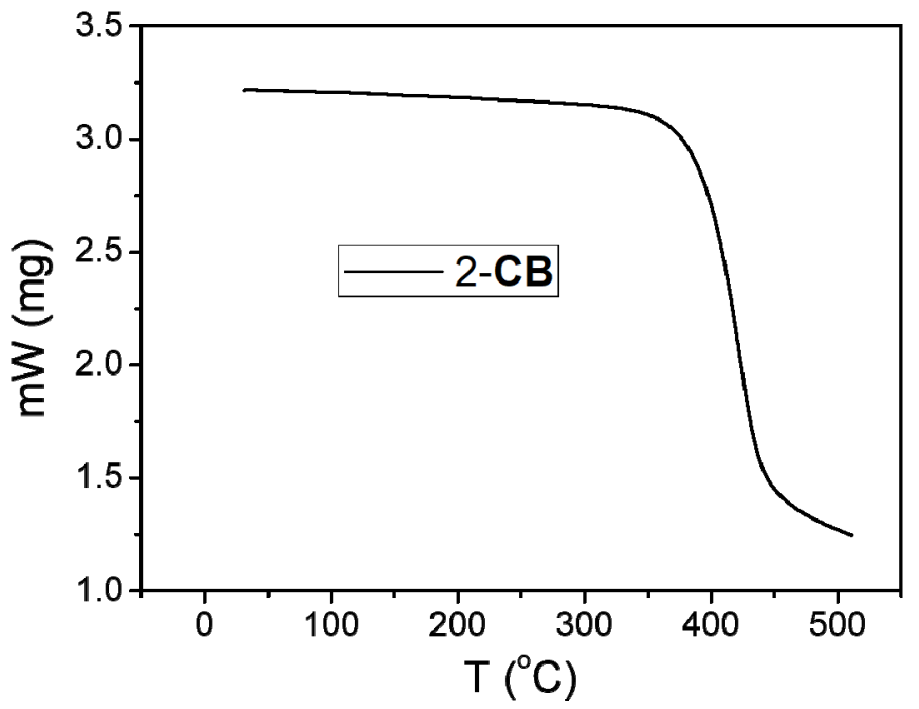

Figure S15. Thermogravimetric analysis of EtP5 $\alpha$ after adsorption of 2-CB. 


\subsection{Single-Component CB Isomer Adsorption Experiments in EtP6 $\beta$}

${ }^{1} \mathrm{H}$ NMR experiments were performed by dissolving EtP6 $\beta$ crystals after vapor sorption. TGA profiles were recorded using EtP $6 \beta$ crystals after vapor sorption.

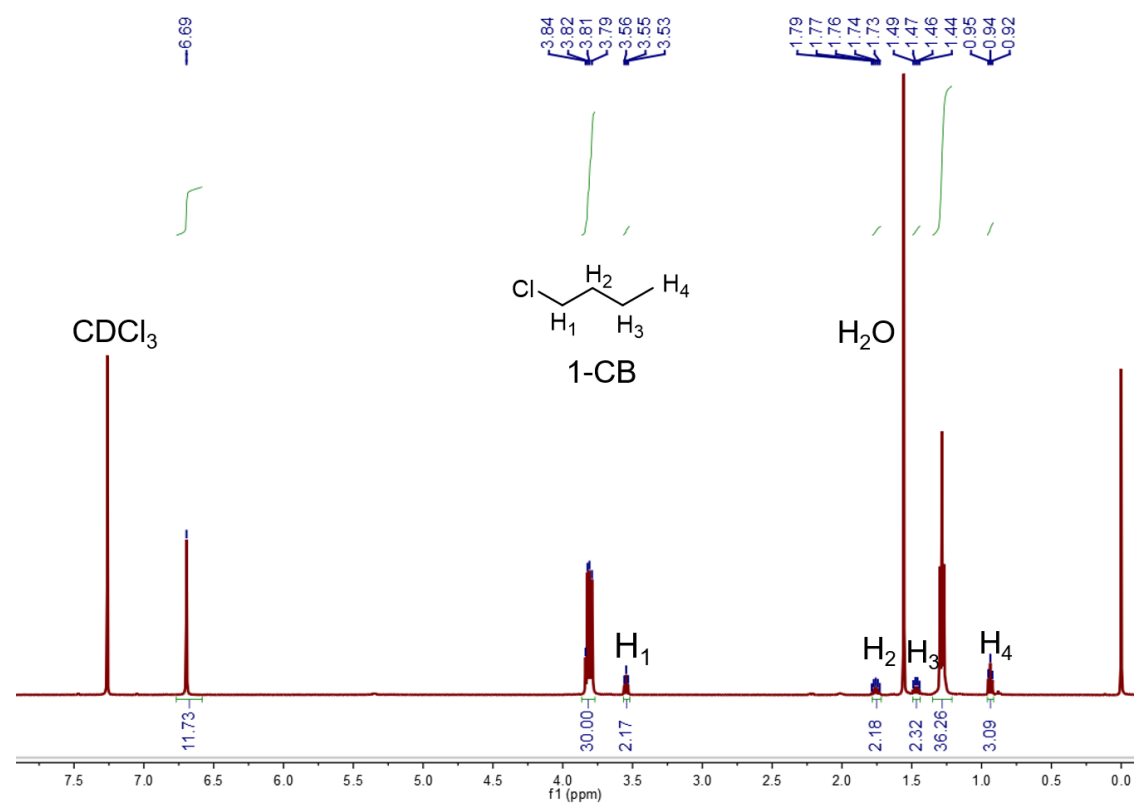

Figure S16. ${ }^{1} \mathrm{H}$ NMR spectrum $\left(400 \mathrm{MHz}, \mathrm{CDCl}_{3}, 293 \mathrm{~K}\right)$ of EtP6 $\beta$ after adsorption of 1-CB vapor.

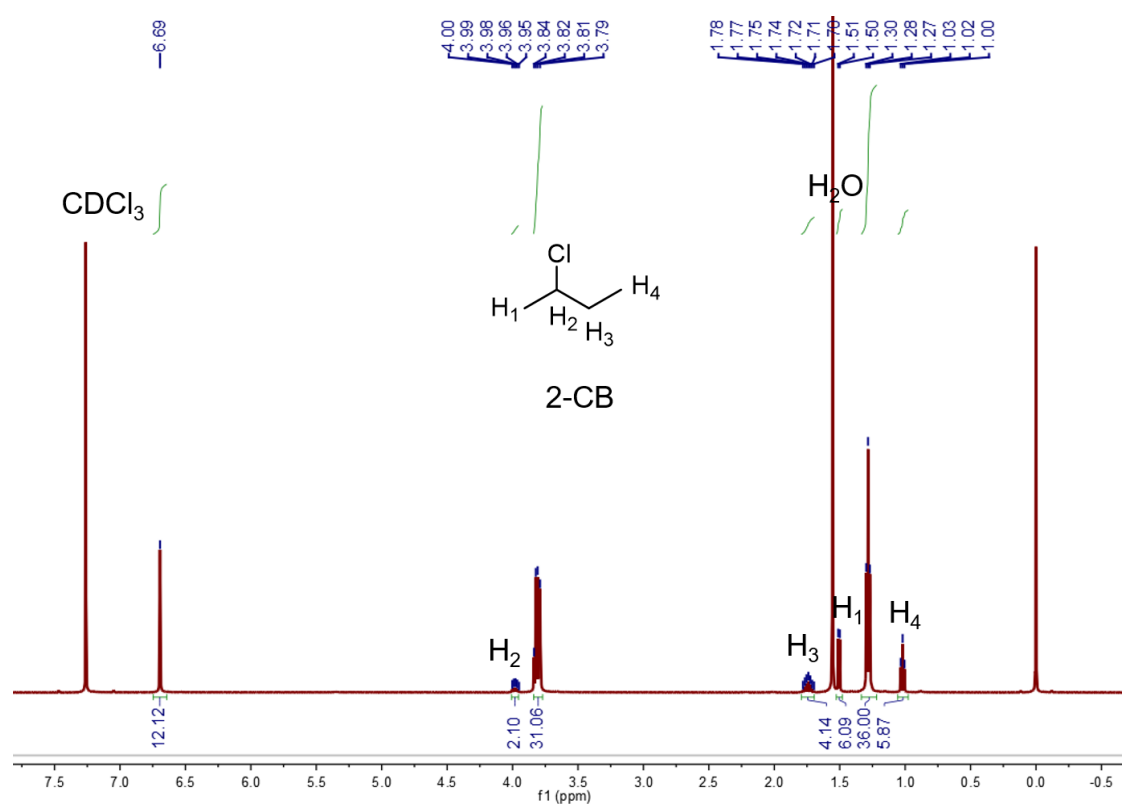

Figure S17. ${ }^{1} \mathrm{H}$ NMR spectrum $\left(400 \mathrm{MHz}, \mathrm{CDCl}_{3}, 293 \mathrm{~K}\right.$ ) of EtP6 $\beta$ after adsorption of 2-CB vapor. 


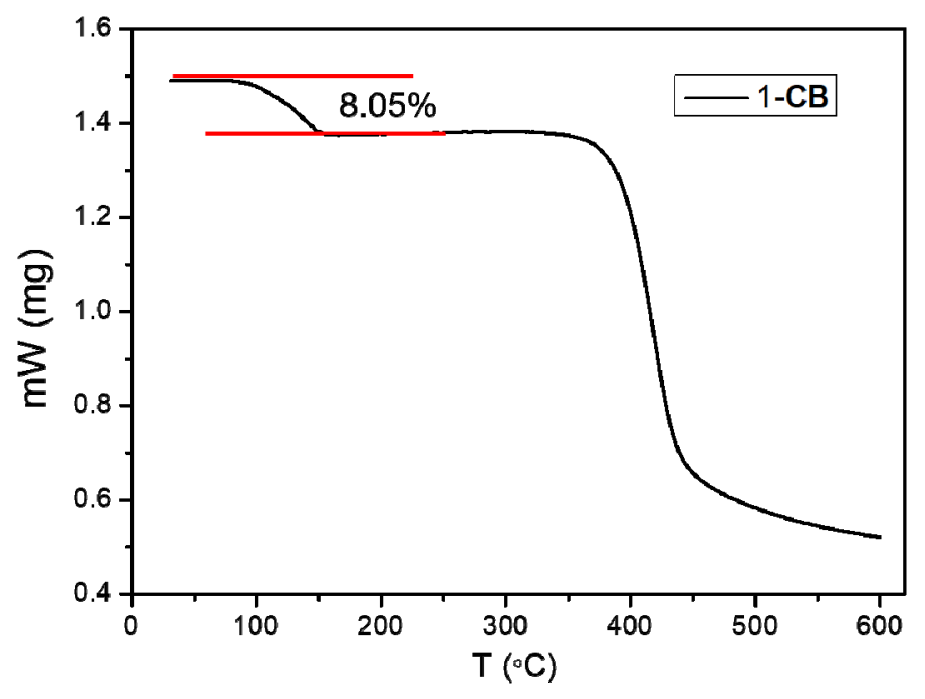

Figure S18. Thermogravimetric analysis of EtP6 $\beta$ after adsorption of 1-CB. The weight loss below $150{ }^{\circ} \mathrm{C}$ can be calculated as 1.01 1-CB molecules per EtP6 molecule.

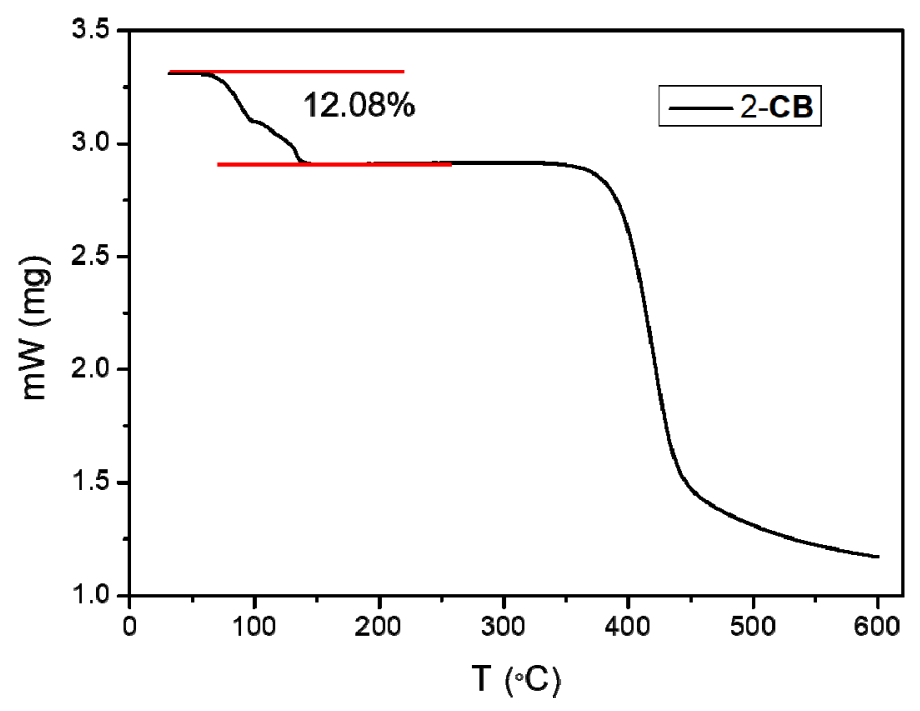

Figure S19. Thermogravimetric analysis of EtP6 $\beta$ after adsorption of 2-CB. The weight loss below $150{ }^{\circ} \mathrm{C}$ can be calculated as 2.05 2-CB molecule per EtP6 molecule. 


\subsection{Structural Analyses after Single-Component Vapor Sorption}

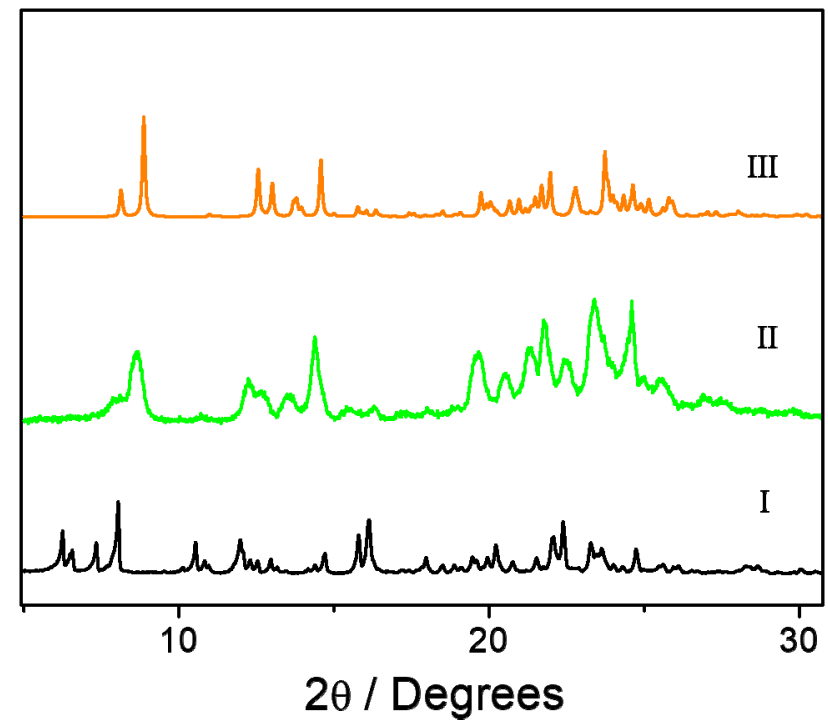

Figure S20. Powder X-ray diffraction patterns of EtP5: (I) EtP5 $\alpha$; (II) EtP5 $\alpha$ after adsorption of 1-CB; (III) simulated from single crystal structure of 1-CB@EtP5.

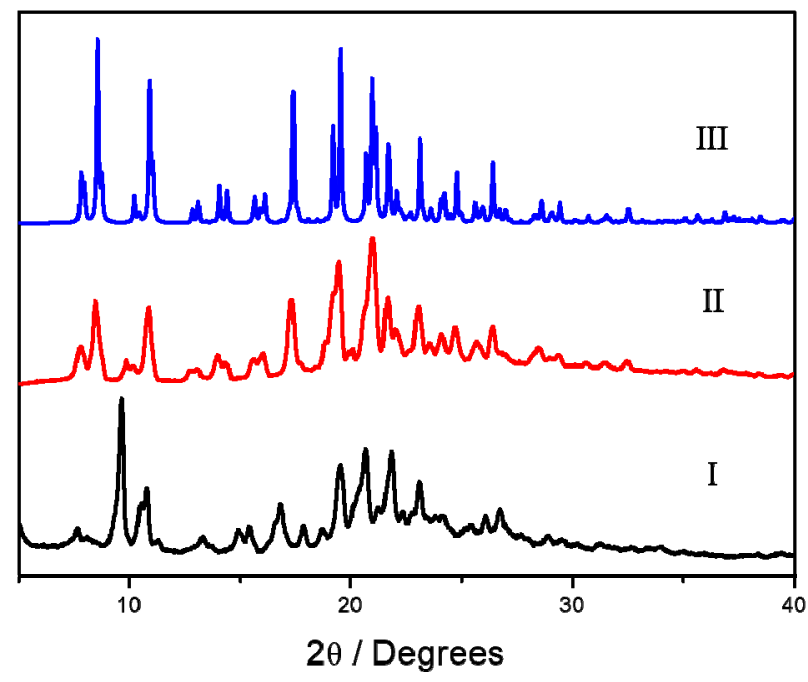

Figure S21. Powder X-ray diffraction patterns of EtP6: (I) EtP6 $\beta$; (II) EtP6 $\beta$ after adsorption of 1-CB; (III) simulated from single crystal structure of 1-CB@EtP6. 


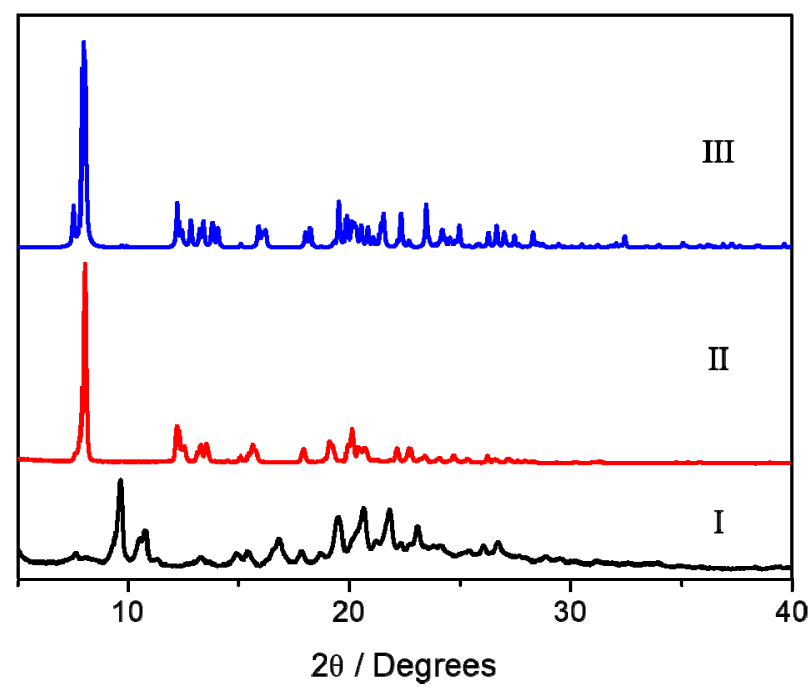

Figure S22. Powder X-ray diffraction patterns of EtP6: (I) EtP6 $\beta$; (II) EtP6 $\beta$ after adsorption of 2-CB; (III) simulated from single crystal structure of (2-CB) $)_{2}$ EtP6. 


\subsection{Uptake from a CB Isomer Mixture in EtP5 $\alpha$ and EtP6 $\beta$}

For each mixture vapor-phase experiment, an open $5 \mathrm{~mL}$ vial containing $0.020 \mathrm{~g}$ of guest-free EtP5 $\alpha$ or EtP6 $\beta$ adsorbent was placed in a sealed $20 \mathrm{~mL}$ vial containing 2 $\mathrm{mL}$ of a CB mixture $(v: v=1: 1)$. Uptake in the EtP5 $\alpha$ or EtP $6 \beta$ crystals was measured hour by hour by completely dissolving the crystals and measuring the ratio of 1-CB or 2-CB to EtP5 or EtP6 by ${ }^{1} \mathrm{H}$ NMR. The relative uptake of $1-\mathrm{CB}$ and 2-CB in EtP5 $\alpha$ or EtP6 $\beta$ was also measured by heating the crystals to release the adsorbed vapor using gas chromatography (headspace method).

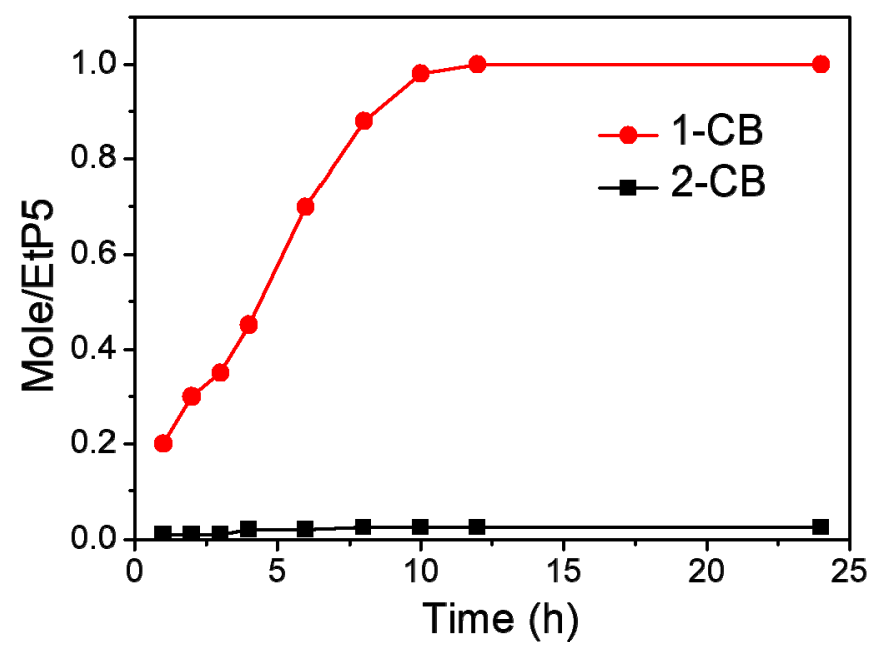

Figure S23. Time-dependent EtP5 $\alpha$ solid-vapor sorption isotherm for CB mixture vapor $(v: v=1: 1)$ at room temperature.

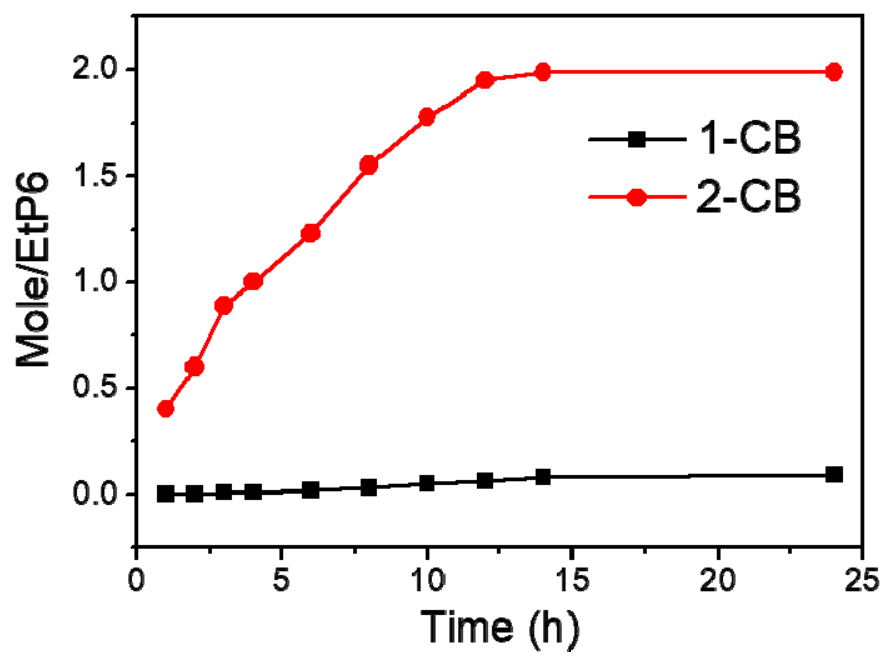

